\title{
Impact of Innovative and highly interactive Online Activities on Energy Efficiency Education
}

\author{
Sarma V. Pisupati ${ }^{1,2}$, Mark Deluca ${ }^{3}$, Marty Gutowski ${ }^{2}$, Wendy Mahan ${ }^{3}$ \\ and Brian Victor ${ }^{3}$ \\ ${ }^{1}$ Energy and Geo-Environmental Engineering Department $/^{2}$ John A. \\ Dutton e-Education Institute/ ${ }^{3}$ Teaching and Learning with Technology \\ (TLT) Division of Information Technology Services \\ The Pennsylvania State University \\ University Park PA 16802 \\ spisupati@psu.edu
}

\begin{abstract}
:
Energy Conservation and Environmental Protection (EGEE 102) course has been taught at Penn State since the fall of 2001. Over the past seven semesters the enrollment has increased from 69 to 760. This course was selected by the University under the "Courseware" initiative to be offered as an online course. To develop the online version of EGEE 102, the Energy and Geo-environmental Engineering Department, the Teaching and Learning with Technology Unit of the University's Information Technology Services and the John A Dutton e-Education Institute have collaborated to generate highly interactive learning objects in an innovative manner.
\end{abstract}

As a part of this endeavor, four home activities (simulations) using Macromedia Flash were developed. The goal of these simulations is to engage students through animations and enable students to calculate their energy consumption, analyze their energy consumption patterns and utility bills, understand the economics of insulation addition, and conduct an energy audit on a virtual home.

Each of the students worked with a unique data set for each of these activities. The data sets for energy consumption of appliances or monthly energy bills for each student are generated using Perl scripts and are retained in the MySQL database. These student specific datasets are delivered through the Flash simulations. The students complete the required activity and submit their results via the Flash interface. The submitted values are automatically compared with the student-specific data sets and the correct numerical answers as calculated by the PHP script. This process minimizes the time required for the faculty to grade the reports, increased faculty efficiency, reduced grading errors, and counters plagiarism as duplicate submissions are ineffective.

Informal student assessment indicated that the highly interactive Flash simulations were a motivational environment enabling comprehension of the cognitively challenging 
material. This paper discusses the approach utilized, and the effectiveness of the methodology in motivating, challenging, and educating the students in energy conservation issues.

\section{Introduction}

In the fall of 2001, the Department of Energy and Geo-Environmental Engineering initiated a drive to educate more students in Energy related subjects outside our majors. A 3-credit general education course on "Energy Conservation and Environmental Protection" (EGEE 102) was developed and offered primarily for nonscience/engineering students. Energy is a vital component of modern society. While people believe that the energy use is the culprit for environmental damage, they are not aware of the methods and principles by which energy conversion devices operate and how an individual can make a difference in the environmental protection. This general education course provides students with necessary knowledge and information on the main operating principles of devices/appliances that are in common use and information on which to make the right decision in selecting the most energy efficient and economical choice. In fall of 2001 the enrollment in the course was 69 and in fall of 2004 the enrollment increased to 760 . This course was taught in multiple sections (six sections in fall of 2004).

\section{Course Objectives and Content}

The main objectives of this course are to 1) provide basic understanding and appreciation of energy efficiency and environmental concepts; 2) learn basic operating principles of day-to-day energy conversion devices; 3) discuss various options to increase energy efficiency; 4) examine ways to save energy, and the environment.

The course was developed with highly interactive and engaging content. The attention span of the students is about 10 minutes into the lecture and decreases after that point (McKeachie, W.J., 1999). The course uses multimedia materials such as video clips followed by class discussion, solving crossword puzzles to reinforce the terminology and problem solving to keep the students engaged. This course also utilizes out-of-class activities in lieu of home formal work.

These group activities have promoted collaborative and joint intellectual learning atmosphere as opposed to traditional lecturing by the instructor. This course entails various simple group-activities in class to reinforce the information presented through formal lectures and reactivate the students' attention (Stage et al., 1998). The group activities included conducting a set of experiments and/or gathering and analyzing the data and presenting the observations later in the form of a written report. These activities can also be in-class demonstrations. 


\section{Problems/issues with increasing class size and online course offering}

With increasing enrollment, logistical problems in creating interactive learning atmosphere in class have increased. Some of the problems are: 1) the number of physical experimental models that are required, 2) the number of students who cannot get utility (energy) bills from home, 3) The possibility of increasing number of students cheating on experimental data interpretation, and 4) the time required to grade and particularly in checking for numerical calculations and cheating by students.

These problems and issues hampered the ability to continue the number and quality of the home activities at the desired level.

The expectations of students of the classroom learning environment today are different from those of their teachers. Even teachers' expectations of their students' work are changing rapidly. With the changing teaching and learning environment, teachers are expected to help students 1) acquire critical skills such as teamwork and presentation skills, 2) prepare them for life long learning and 3) use information technology advances for learning. Therefore, effective pedagogical practices require instructors to use whatever technology is appropriate in order to assist student learning. The use of electronic technology provides faculty with a number of ways in which learning resources can be developed and used to enrich the learning experience. It also facilitates providing these resources on a $24 / 7$ basis without time constraints.

\section{Objective of this Work}

Objective of this work was to address the issues and develop highly interactive virtual activities using Macromedia Flash simulations. This is customized in such a manner that each student will receive certain values or variables that are specific to a student. These values are stored in a database to check against the student submissions to check for possible cheating and to reduce time required for grading the activities.

\section{Methodology and Tools Used}

\section{Instructional Design}

The online simulations were based on activities that students in the face-to-face course completed as graded assignments. Since the basic instructions and procedures were already completed and allowed successful completion, the focus of instructional design was how to best adapt these activities to an online environment. Specific concerns included: providing enough organization and detail to support the online learner, using instructional messages and text design to increase the clarity of the steps involved in each simulation, using graphical representations for the more difficult concepts, and ensuring consistency in the design of the four simulations.

For all three simulations, the problem-solving process was broken down into small, organized steps, and these steps were listed in advance as a means of making the students aware of what was required (Dick \& Carey, 1996). Each step was presented on a separate 
screen and was clearly indicated throughout the simulation with bolded headings and signaling words such as Step 1, Step 2, etc.(Morrison, Ross \& Kemp, 2004). Directions were given in an active rather than a passive voice, and were worded in a concise manner that avoided the overuse of subordinate clauses (Hartley, 2004).

\section{Macromedia Flash Simulation Development}

Flash was chosen as the media to deliver the activities because of its ubiquity (its content is accessible by $98.2 \%$ of internet-enabled computers*), and for its ability to deliver rich interactive content efficiently, while at the same time having enough back-end capability to communicate with a database. Given the nature of this course in a classroom setting with lots of fun, hands-on experimentation and plenty of out-of-classroom activity Flash was the natural choice to allow students to have the same type of experiences in an online environment. The activities allowed students to do everything from exploring rooms in a 'virtual home' in order to gain energy-usage information for common household appliances/devices, to conducting a 'virtual experiment' in order to determine the best insulation method, to visiting a 'virtual home improvement center' in order to compare prices and R-values of various insulation materials.

The challenge from a design perspective was to capture the fun, hands-on essence of the classroom course while keeping students engaged and focused on the learning at hand. As mentioned previously, plenty of user interaction was built into each activity to allow students to control the speed at which they were completed. A simple, user-friendly interface was consistent throughout to eliminate the need for students to have to re-learn navigation rules, and special "help" buttons were included for more difficult sections to add an extra level of detail for those who needed it. To keep things fun, caricatures were developed and sprinkled throughout each activity depicting the instructor in many comical situations; from being half-buried in an avalanche of gas and electric bills, to wearing a fur coat in the Alaskan wilderness. Judging from initial student response to the activities, the interactivity and fun built into them was a success.

The challenge from the Flash end of data transfer was to ensure that data was sent to and received from the database correctly. Each activity involved two-way communication with the database. To reduce the risk of students sharing information, each activity contained key pieces of data randomly generated and sent from the database to the Flash file. Once received by Flash, the data was manipulated and presented in a way that students could use for the task at hand. The result is unique data displayed for each student.

\section{PHP scripts and My SQL database Development}

The Flash movies were located on a secure web server that was tied into the University's Kerberos authentication system, employed by other University services such as email. By using it, need to set up another set of userids and passwords was eliminated.

* SOURCE: http://www.macromedia.com/software/player_census/flashplayer/ 
When a student logged into the web site, PHP scripts captured their userid and used it to query the MySQL database for data unique to the student. For example, in the activity in which students collected energy use data in a virtual house, energy consumption values of five appliances were coded differently for each student. The student then submitted these values back to the database, allowing us to ascertain whether each student collected his/her own data.

Different PHP scripts queried the students' submissions from the database and created reports for instructors and teaching assistants. Any calculations the students were expected to perform, the scripts mimicked. A teaching assistant would log into the system, choose a class section, and click on a hyperlinked student's name. The work the student had submitted was summarized in a web page. Thus, it took only a short time for a TA to grade each student's work.

Students typically like to verify that an assignment is successfully 'handed in.' Links were provided for web pages for each student to see a report of what he/she submitted. If the results weren't what he/she expected, the student could re-submit or contact an instructor for help. This process ensured, and assured students that their submissions were recorded the way they would like to submit.

Activity 1- Estimation of Residential Energy Consumption- The leaning objectives of this activity are 1) To learn the name plates of appliances for power consumption, 2) to develop to gather power consumption of various household appliances and calculate the total energy consumption and cost of energy for one semester. Prior to developing this simulation, students were asked to collect power consumption from the name plates of any 15 appliances that they use at home/dorm room/apartment and estimate the energy consumption for one semester. In addition to this data gathering and estimation, students were also asked to analyze their usage and list ways in which they can reduce energy consumption and quantify their potential savings. The potential problems for students are 1) the number of appliances that they use in dorms is not as many as they would in an apartment, 2) most of the dorms have same type and rating appliances which increases the potential for exchange of information and cheating and 3) some of the appliances may not have all the information required to calculate the power consumption.

The Flash simulation for this activity involves gathering power consumption information on five mandatory appliances (and ten other appliances of the students' choice from various rooms. The power consumption data for the mandatory five appliancesrefrigerator, oven, water heater, clothes washer and dryer are generated for each student within a reasonable range using Perl script and stored in a database. As the student logs in to complete the activity and selects the appliance/device, the student-specific data are displayed on the nameplate for the five mandatory appliances. The power consumption of rest of the appliances/devices is the same for all the students. However, each individual student has to choose only ten other appliances/devices in this virtual home. Students initially see the overall configuration of the house as shown in Figure 1a (screen 2 of the simulation). They click on any room on the screen and the turn on the light and choose the appliances/devices of their choice and click on them to see the nameplates. This gives 
enough flexibility and freedom for each student to choose appliances/devices of their liking to complete the activity. This makes the learning process fun and educational. After the appliances are chosen, and the data are noted down, the students performed the calculations to estimate the energy consumption. These answers are entered on the next screen in the Flash simulation. When the submit button is clicked all the answers entered are recorded back in the data base. 

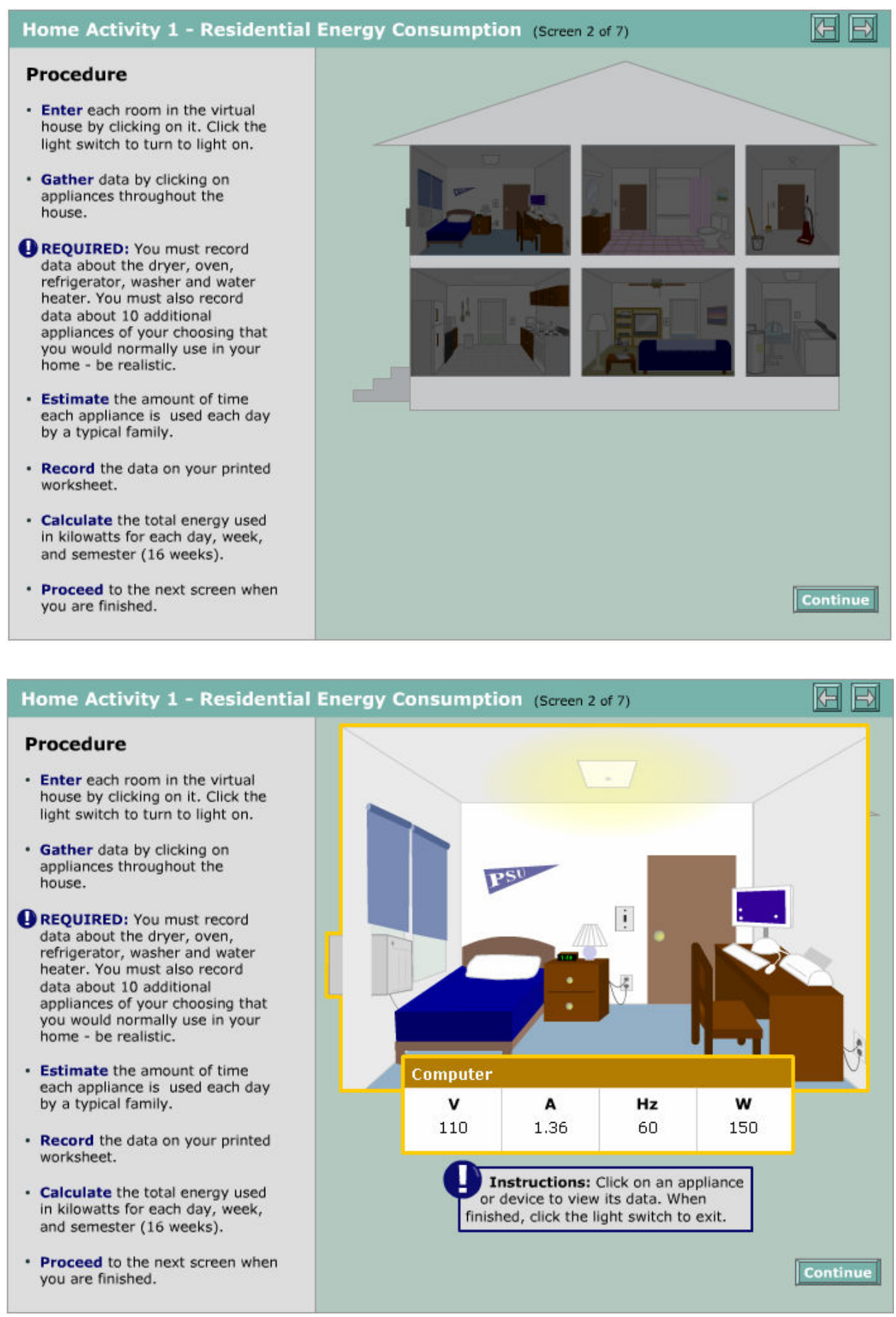

Figure 1.Screenshots of Home Energy Consumption Activity Flash Simulation a) shows the whole house and appliances b) shows the nameplate information.

At the time of grading, when an instructor or a Teaching Assistant logs into the system, a PHP script calculates the answers based on the original power consumption values 
generated by the script for the five mandatory appliances and lists those values along with the submissions as shown in Figure 2. The script will also calculate the energy consumption for rest of the devices based on the power consumption and the time of usage (student's input). The answers submitted by the student for the results and analysis are shown in Figure 3.

\section{Activity 2- Analysis of Home Energy Consumption}

The learning objectives of this activity are 1) to develop skills to read and understand the utility bills 2) to quantitatively analyze the home energy usage pattern and 3) to understand the cost and environmental implications of their energy use.

Prior to this Flash simulation development, Students were asked to collect one year (12 months) of utility bills for all the home energy sources they use. Students analyzed the seasonal variations in the total energy and the type of fuel used and they determined the relative percentages of energy sources and the relative costs of each. They also determined the environmental impact of their energy use. Often the problems were nonavailability of their home energy bills for the past 12 months. Tracking the bills for a class of 150 to prevent cheating was a difficult task.

In this activity development, virtual utility bills were generated for every student and the data were stored in the MySQL database. Figure 4 below shows two "virtual electric bills" from requiring students to track gas and electric usage for one year. The tabs (monthly) at the bottom provided the student with the monthly electric consumption, generation, transmission and distribution costs. It can be seen from the figure that the random data (in this case KWH for February) is different for each user. Because most of the other data on the bill is tied to this number, each student receives a unique utility bill. On the back end, the database tracks which randomly-generated numbers belong to each student so grading is fast and efficient. Similarly gas bills were also generated. The students tabulated the data, graphed and analyzed the data and answered a series of questions. Figure 5 shows a screen with five questions. The students have to perform the calculations on their own. The instructions only provide guidelines on how to perform the calculations.

Once experiments were conducted, observations were made and calculations were performed, students submitted their data back to the database. A final check was built into the Flash file, and if there were any problems communicating with the database students immediately got a message alerting them to the error. If no problems existed, they received a message indicating that their data was successfully received. 


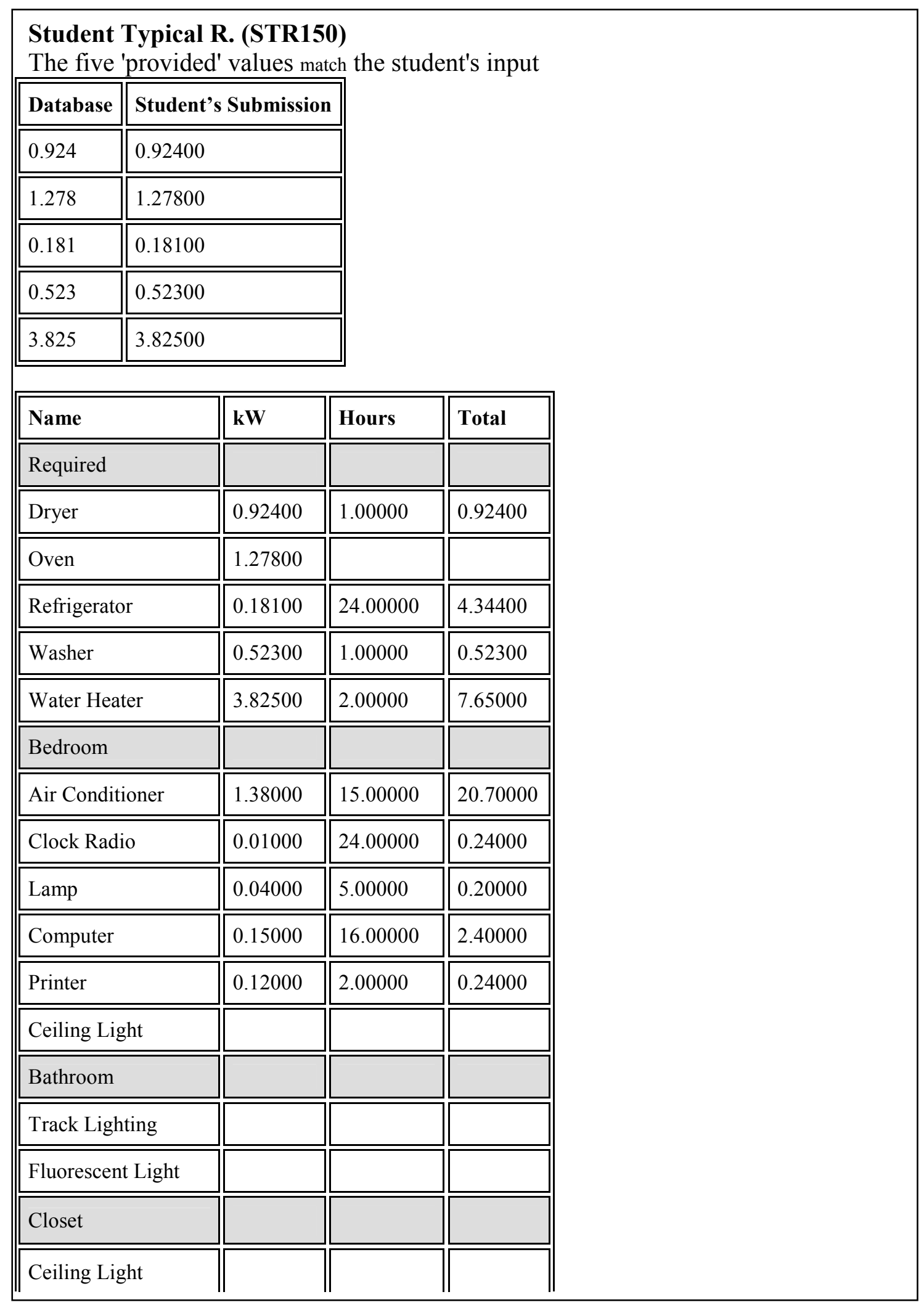

Figure 2 Instructor's view of the data submitted by a student for Home Energy Consumption

"Proceedings of the 2005 American Society for Engineering Education Annual Conference \& Exposition Copyright $\bigcirc$ 2005, American Society for Engineering Education” 


\section{Student Typical R. (STR150)}

Answers to the questions

1. Determine the total kWh consumed in ONE DAY: match (script: 40.776 / student: 40.776)

2. Determine the total kWh consumed in ONE WEEK: match (script: 285.432 / student: 285.432)

3. Determine the total kWh consumed in ONE SEMESTER (16 weeks): match (script: 4566.912 / student: 4566.912)

4. Based on the U.S. average price of 8.5 cents per kWh, estimate your cost of energy per semester (total energy consumed $\mathrm{x}$ cost per kWh). match (script: 388.18752 / student: 388.18752 )

5. What percentage of the total energy consumption is consumed by lighting? (student:

2.452422993918 / script: 2.00000 )

6. What percentage of the total energy consumption is consumed by appliances/lighting? (student: 97.547577006082 / script: 98.00000)

7. Identify specific ways...

I could turn the printer off when it is not in use and cut its consumption by $50 \%$ to 1 hour/day. I could open the windows when there is a cold breeze outside and cut the consumption of the air conditioner by $20 \%$ to 12 hours/day. I could turn the computer off when it is not in use and cut its consumption by $25 \%$ to 12 hours/day.

Figure 3 Instructors view of answers submitted by students for Home Energy Consumption Activity

\section{Activity 3: Effect of Insulation on Home Energy Costs}

This project consists of three parts. Students perform the experiment using an interactive computer-based multimedia simulation. Details of this project can be seen in elsewhere (Pisupati et al., 2004).

Part 1: To determine the most effective type of insulation (R-Values).

This was accomplished by completing a virtual experiment with several boxes with different insulation materials all heated by incandescent bulbs inside the box. The internal box temperature is recoded by the student (actually read off the virtual thermometers), and graphed as a function of time; permitting them to elucidate the significance of R-values. The R-value of a composite wall is also calculated.

Part 2: To determine the cost effectiveness of various insulation materials.

This objective is accomplished by obtaining current purchase price of five different insulation materials used in the simulation, calculating the heat loss using the heat conduction equation and plotting a chart of reducing heat loss with increasing insulation (costs) and recommending the most cost effective insulation. Current costs of the insulation materials are student obtained by visiting a home improvement store. 


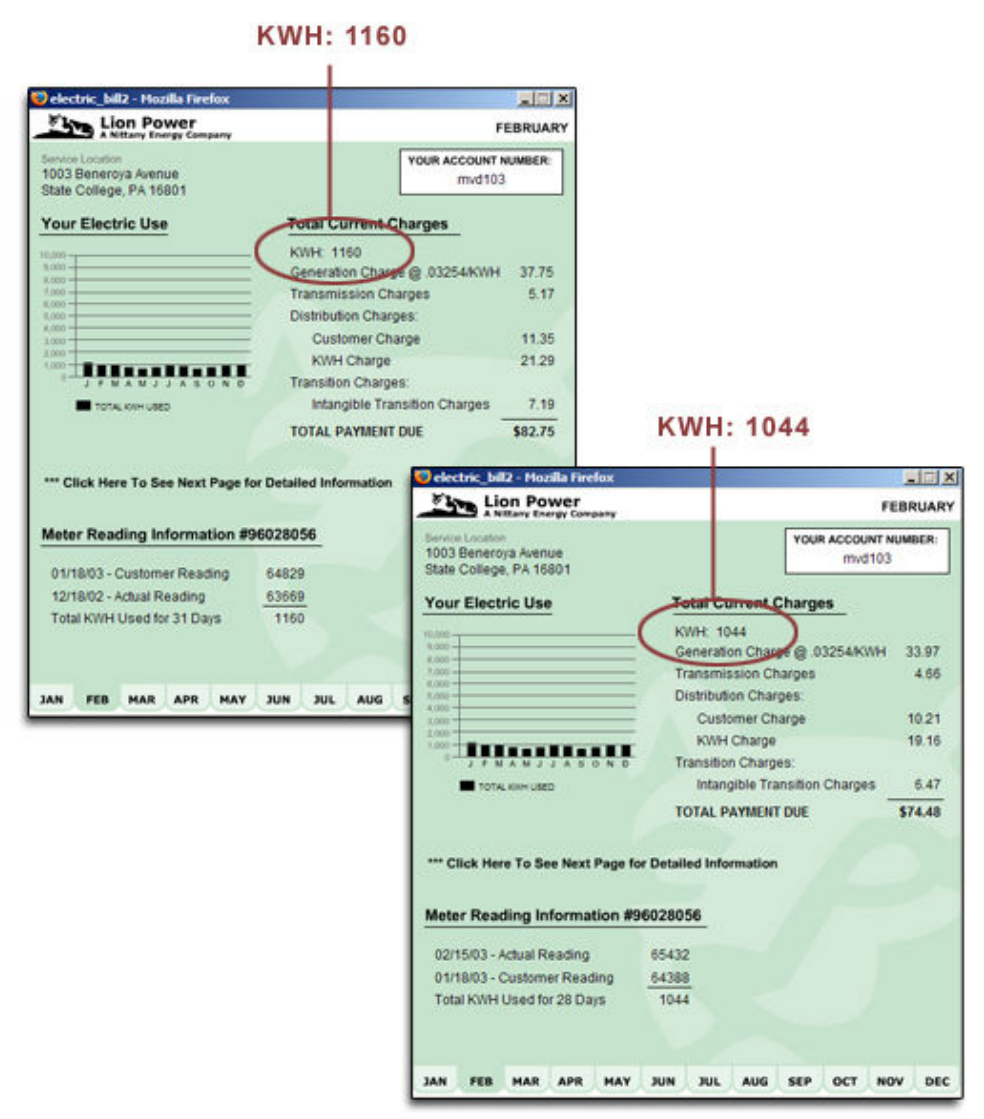

Figure 4 The Flash activity receives unique, randomly-generated data from the database - in this illustration, note that February KWH figures are different for each student.

Part 3: To extend and apply the knowledge gained in Parts 1 and 2 by selecting a location, house size, type (single level or bi-level), number and type of windows, and the type of fuel used. Thus, enabling the student (via the simulation to study the effect of various parameters) to calculate the payback period. 
Step 4: Respond to the following seven questions.

1. Convert total gas and electricity consumption to BTU's (assume that 1,000 $\mathrm{cu}$. ft. of natural gas is one million BTU's and that $1 \mathrm{kWh}=3,412 \mathrm{BTU}$ 's).

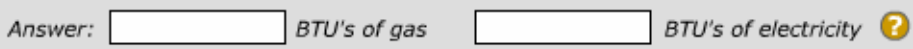

2. Determine the cost of one million BTU's from each fuel (gas and electricity).

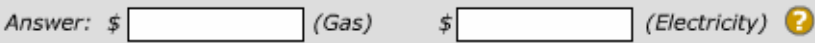

3. Determine the total energy consumption (BTU's) in a year and calculate the average cost of one million BTU's.

Answer: (Total BTU's) (Average Cost of 1 million BTU's) ?

4. What is the percentage of energy coming from each fuel?

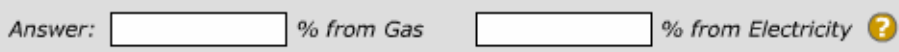

5. What is your total monthly average energy bill? Answer: $\$ \square$ ?

Figure 5 A screenshot of the questions where the students enter their answers in to Flash

\section{Assessment}

These highly interactive Flash simulations were used in fall of 2005 in five sections of resident instruction classes. In the first simulation, certain browser and flash version problems were encountered that were fixed in the second simulation. The student has given positive input about these activities. A formal feedback was collected at the end of the semester. However, the results are not available yet. Student responses will be discussed at the meeting.

The feedback from the Teaching Assistants was very positive. This method of submissions and Perl scripts providing the answers has reduced the grading time by half. That is a substantial savings for the Department.

\section{Summary}

Four highly interactive activities were developed using Macromedia Flash to address the logistical problems with increasing enrollment. Each of the students worked with a unique data set for each of these activities. The data sets for energy consumption of appliances or monthly energy bills for each student are generated using Perl scripts and are retained in the MySQL database. These student specific datasets are delivered through the flash simulations. The students complete the required activity and submit their results via the Flash interface. The submitted values are automatically compared with the student-specific data sets and the correct numerical answers as calculated by the 
PHP script. This process minimizes the time required for the instructor to grade the reports, increased faculty efficiency, reduced grading errors, and counters plagiarism as duplicate submissions are ineffective. Informal student assessment indicated that the highly interactive Flash simulations were a motivational environment enabling comprehension of the cognitively challenging material.

\section{Acknowledgements:}

The authors acknowledge the support of John Harwood and Marilynne W. Stout of the Teaching and Learning with Technology (TLT) of Informational Technology Services and David DiBiase, Director of e-Education Institute at Penn State for their consistent support in developing state-of the teaching and learning tools to make teaching and learning a pleasure at the University.

\section{References:}

Dick, W. \& Carey, L. (1996). The systematic design of instruction (4th ed.). New York: Longman.

Hartley, J. (2003), In Jonassen's (ed.) Handbook of research on educational communications and technology, New York: MacMillan, 917-947.

McKeachie, W.J. (1999), Teaching Tips, Strategies, Research, and Theory for college and University Teachers. 10th ed.: Houghton Mifflin Company, New York.

Morrison, G. R., Ross, S. M., \& Kemp, J. E. (2004). Designing effective instruction (4th ed.). Hoboken, NJ: John Wiley \& Sons.

Pisupati, S. V., Mathews, J. P., DiBiase, D., Scaroni, A. W., (2004) " An Assessment of Active and Project Based Learning in Energy Conservation Education for Non-Technical Students" Proceedings of the 2004 American Society for Engineering Education Annual Conference \& Exposition, American Society for Engineering Education, Session \# 2433, June 20-23, 2004, Salt Lake City, UT.

Stage, F.K., Muller, P.A., Kinzie, J. and Simmons, A (1998) ., Creating Learning Centered Classrooms: What does Learning Theory Have to Say? 26(4): p. 84.

\section{Biographical Information}

SARMA V. PISUPATI is an Associate Professor of Energy \& Geo-Environmental Engineering Department and a Faculty Fellow of the John A Dutton e-Education Institute of the College of Earth and mineral Sciences. He is Chair of the General Education Program of the EGEE Department and has been teaching undergraduate and graduate courses at Penn State University since 1992.

MARK DULUCA is a Multimedia Developer in the Teaching and Learning with Technology (TLT) wing of the Information Technology Services (ITS) at The Pennsylvania State University.

MARTY GUTOSKI is a Research Assistant in the e-Education Institute of the College of Earth and Mineral Sciences. Mark is the web systems administrator for the e-Education Institute in the College and the Gould Center for Geography Education and Outreach in the Geography Department at the Pennsylvania State University. 
WENDY L. MAHAN is Instructional Designer in the in the Teaching and Learning with Technology (TLT) wing of the Information Technology Services (ITS) at The Pennsylvania State University. Wendy is responsible for the instructional design part of various online courses.

BRIAN VICTOR is a Senior Applications Programmer/Analyst with the Teaching and Learning with Technology (TLT) wing of the Information Technology Services (ITS) at The Pennsylvania State University. 